Georgia State University

ScholarWorks @ Georgia State University

$12-27-2016$

\title{
Interventions for Healthy Aging among Mature Black Lesbians: Recommendations Gathered through Community-Based Research
}

Kristie L. Seelman

Georgia State University, kseelman@gsu.edu

Mary Anne Adams

Georgia State University, madams9@gsu.edu

Tonia C. Poteat

Johns Hopkins University, tpoteat@jhu.edu

Follow this and additional works at: https://scholarworks.gsu.edu/ssw_facpub

Part of the Social Work Commons

\section{Recommended Citation}

Seelman, Kristie L.; Adams, Mary Anne; and Poteat, Tonia C., "Interventions for Healthy Aging among Mature Black Lesbians: Recommendations Gathered through Community-Based Research" (2016). SW Publications. 76.

https://scholarworks.gsu.edu/ssw_facpub/76

This Article is brought to you for free and open access by the School of Social Work at ScholarWorks @ Georgia State University. It has been accepted for inclusion in SW Publications by an authorized administrator of ScholarWorks@ Georgia State University. For more information, please contact scholarworks@gsu.edu. 
Interventions for Healthy Aging among Mature Black Lesbians:

Recommendations Gathered through Community-Based Research

Kristie L. Seelman Mary Anne Adams

Georgia State University

Tonia Poteat

Johns Hopkins University

The Version of Record of this manuscript has been published and is available in the Journal of

Women \& Aging, as of December 27, 2016, at http://www.tandfonline.com/doi/abs/10.1080/08952841.2016.1256733

\section{Manuscript word count: 7,816}

\section{Author Note}

Kristie L. Seelman, School of Social Work, Georgia State University; Mary Anne Adams, School of Public Health, Georgia State University; Tonia Poteat, Johns Hopkins University, Bloomberg School of Public Health.

This research was supported by the Georgia State University School of Public Health.

Correspondence concerning this article should be addressed to Mary Anne Adams, School of Public Health, Georgia State University, Atlanta GA 30303. E-mail:

madams9@gsu.edu 


\begin{abstract}
Black lesbians have unique needs for gerontological services that reflect their experiences of intersectional oppression and resilience. Yet, there is a major knowledge gap about interventions that promote healthy aging in this population as voiced by Black lesbians themselves. To address this need, 100 Black lesbians, ranging in age from 41 to 91, participated in focus groups in Atlanta, Georgia, to discuss their experiences of aging, health needs, and recommendations for interventions. Through thematic analysis, we identified six themes related to suggested approaches for healthy aging interventions. We discuss implications of these findings for aging practice and future research.
\end{abstract}

Keywords: aging; interventions; Black/African American; lesbian; health 
As they age, Black lesbians face a number of health disparities related to lifetime discrimination, socioeconomic disadvantage, and inadequate access to health care, among other factors (Fredriksen-Goldsen et al., 2011; Woody, 2014, 2015). The overlapping axes of gender, race, and sexual orientation, as well as other identities, contribute to the unique, intersectional needs of this population in relation to healthy aging. Yet, there is relatively little research that studies the characteristics of aging interventions that would effectively serve this community particularly knowledge that draws from the lives of mature Black lesbians. The present study addresses this gap in the knowledge base through analysis of focus groups with 100 Black lesbians age 40 years and older living in metropolitan Atlanta, GA.

\section{Literature Review}

There is a remarkable need for research about interventions to promote health and wellbeing among Black lesbians, especially in relation to aging. Black women are more likely to experience cardiovascular disease, obesity (Office of Research on Women's Health, NIH, 2014), and accelerated biological aging (Geronimus et al., 2010), as well as a shorter overall life expectancy (Office of Research on Women's Health, NIH, 2014) compared to white women. In terms of sexual orientation, a growing knowledge base indicates heightened risks for disability, mental distress (Fredriksen-Goldsen et al., 2011; Gonzales \& Henning-Smith, 2015), obesity, and cardiovascular disease among midlife and older lesbians of all races compared to heterosexual women of similar age (Fredriksen-Goldsen et al., 2011). Although such knowledge demonstrates unique health burdens for Black women and for lesbians, the evidence base largely has not examined the particular health of Black lesbians related to aging.

Despite limited research in this area, the emerging knowledge base suggests that Black lesbians face heightened risks for disability and mental distress compared to white lesbians 
(Fredriksen-Goldsen et al., 2011). Qualitative research with older Black lesbians sheds light on struggles with invisibility, isolation, alienation, nondisclosure of sexual identity, intersectional discrimination, grief and loss in connection to aging, and rejection by religious communities, among other concerns (Woody, 2014, 2015). Black lesbian, gay, bisexual, and transgender (LGBT) elders are more likely than white LGBT elders to have HIV, high blood pressure, and to be obese, as well as to experience neglect (Fredriksen-Goldsen et al., 2011). A lifetime of exposure to societal stigma, discrimination, stereotyping, and harassment, as well as efforts to conceal aspects of themselves from others, contribute to mental health stressors (McIntyre, Antonucci, \& Haden, 2014).

Access to health care and gerontological services is an issue for older Black lesbians, impacted by a lack of cultural competency among providers, a history of oppression within service provision (Van Sluytman \& Torres, 2014), and a reasonable hesitance among Black women in seeking help from health care providers due to fear of discrimination (Li, Matthews, Aranda, Patel, \& Patel, 2015). Others have documented concerns about finances and the lack of long-term care options that promote community among older Black lesbians (Zuna Institute, 2010). These factors can further contribute to the exacerbation of health challenges for Black lesbians in late life, complicating the course of aging.

At the same time, Black lesbians are demonstrably surviving and thriving, showing incredible resilience in the face of all of the risk factors discussed above (Woody, 2015). Older Black LGBT people are engaging in health promotion behaviors as frequently as whites, including a majority engaging in weekly moderate physical activity (Fredriksen-Goldsen et al., 2011). They develop strategies for not "lingering" on situations that cause psychological distress (Woody, 2015). Experiences of oppression experienced across the life course, including racism 
and sexism, may help them better respond to ageism later in life (Woody, 2014). By

understanding strategies for harnessing existing resilience and strengths among Black lesbians, gerontologists and other helping professionals can actively counter prevailing cultural myths of Black women and turn to the community to develop solutions.

Despite the unique health risks for Black lesbians in late life, scant research has examined particular interventions that may promote healthy aging for this population, especially as recommended by older Black lesbians themselves. Considering the richness of strengths within this population, there are myriad opportunities for creating community-driven efforts to promote healthy aging in this community. Such a perspective is based in Black feminist theory, which is a critical social theory rooted in the knowledge and lived experiences of Black women that aims to disrupt the injustices and institutionalized oppression impacting Black women and similarly disenfranchised groups (Collins, 2009). Studying the experiences of older Black lesbians importantly calls attention to intersectionality - the idea that we each hold multiple, overlapping identities that inform our lived experiences, and any analysis of race, sex, or class must pay attention to other dimensions of marginalization (Crenshaw, 1989). Without attention to intersectionality, we risk erasing, ignoring, and distorting the lived experiences of older Black lesbians and other multiply marginalized populations.

We build upon these theoretical foundations to call attention to the voices of mature Black lesbians as they describe what would be most helpful to promote their healthy aging. In this research, we set out to listen to the experiences of older Black lesbians, age 40 years and older, to give witness to their lives, their wisdom, and their strategies for thriving as they age. Our research question is: What do mature Black lesbians recommend as effective approaches for promoting healthy aging in their community? 


\section{Methodology}

\section{Study Procedure}

This mixed methods project was designed and coordinated by the second (Mary Anne) and third (Tonia) authors. Between May and June 2014, 14 focus groups were held in the Atlanta, Georgia, metropolitan area with the intention of gathering information on the health and aging needs of mature Black lesbians. To participate, one had to be a woman age 40 or older residing in metro Atlanta, identify as Black and/or of African descent, and identify as lesbian, same-gender-loving, or gay. The women were recruited through networks of Black LGBT organizations and key gatekeepers in the region using purposive and referral sampling. The sampling frame encompassed both mid-life and older Black women to capture a comprehensive perspective of the needs for aging interventions across age cohorts. Including mid-life women's perspectives is important here due to the various forms of oppression, stress, and consequent health challenges that Black women face across the lifespan that contribute to a shorter overall life expectancy compared to white women. Thus, interventions to promote healthy aging among Black women may need to effectively reach women in mid-life, as well as in late life, so gathering perspectives from both groups was perceived to be critical. This study's procedures were approved by the Georgia State University Institutional Review Board.

The research team used focus groups rather than individual interviews as a way to encourage deep discussion amongst diverse groups of aging Black lesbians. Previous research has supported the effectiveness of utilizing focus groups with older Black women (Weitzman, Dunigan, Hawkins, Weitzman, \& Levkoff, 2001), for studying health-related needs (Wilkinson, 1998) and for discussion of sensitive topics, such as lesbian sexual health (Farquhar \& Das, 1999). Each focus group consisted of between 4 - 10 women, lasted between 1.5 - 2 hours in 
length, and was run by a researcher identifying as a Black lesbian feminist. Before the discussion began, the researcher reviewed consent procedures and the study's risks and benefits and obtained written consent from participants. The researcher distributed a demographic survey prior to the start of the focus group. Focus groups were audio recorded and later transcribed verbatim, with personal identifiers removed. Each participant was offered $\$ 50$ as compensation, as well as reimbursement for transportation.

\section{Sample}

Among the 100 women participating in the focus groups, age ranged from 41 to 91 , with a mean age of 54. Eighty-four of the women had at least some college education. The majority of the women $(n=58)$ were currently employed, while 29 were unemployed and seven were retired. The mode household income was $\$ 30,001-\$ 60,000(n=39)$, followed by $\$ 10,001$ $\$ 30,000(n=23), \$ 60,001-\$ 100,000(n=16)$, and $\$ 10,000$ or less $(n=13)$. One in five $(n=20)$ were uninsured. About one-third $(36 \%, n=36)$ had at least one disability, and about a quarter of the disabilities were mental health related.

\section{Data Analysis and Researcher Reflexivity}

The focus group transcriptions were uploaded into NVivo 10 for qualitative analysis. The first author (Kristie) conducted content analysis (Patton, 2002, p. 453) utilizing structural coding, which involves qualitative coding that aims to answer the a priori research question of interest (Saldana, 2009). In many of the focus groups, the facilitator asked a question along the lines of, "If there was unlimited funding to help Black lesbians as they age, what type of program would you like to see?" Many of the responses to this query were relevant to our research question and therefore were used to form the themes detailed in this paper. However, relevant data were also drawn from other portions of the focus group conversations. 
Kristie shared tentative themes with Mary Anne and Tonia for review, and revisions were made based upon feedback. This was a critical step in our methodology due to the positioning (Sanchez, 2006) of each of us as researchers: although Kristie took the lead on conducting the qualitative data analysis, her positioning as a 35-year-old white, queer woman impacts her analysis in important ways. Mary Anne and Kristie have had conversations about how Kristie's identities - particularly her race and age - are of notable difference than the women participating in this project and call for critical reflexivity within the research process to actively counter racism, ageism, and other forms of oppression that are replete in research focused on Black women and older adults. Further, Kristie was not involved in the study conceptualization or data collection, and so checking interpretations of the data with Mary Anne and Tonia was a critical step, particularly given the community-based nature of the study design. Mary Anne, who identifies as a Black lesbian feminist and has an expertise in social work, public health, community-based research, LGBT health, and health disparities, conceptualized the original study (with Tonia) and carried out 12 of the focus groups. Tonia is an academic researcher in LGBT public health and a medical provider who identifies as a Black lesbian. She conceptualized the study with Mary Anne based on their mutual commitment to the health and well-being of aging Black lesbians.

\section{Results \& Discussion}

Our analysis produced six themes related to suggested characteristics of interventions to promote healthy aging among Black lesbians: (a) encouragement of community and human connection; (b) holistic care, mind-body techniques, and complementary \& alternative medicine; (c) economic interventions; (d) information and education about aging and health services and legal needs tailored to mature Black lesbians; (e) preferred provider identities and competencies; 
and (f) intergenerational approaches. Some of the themes focus on particular emphases of interventions (e.g., economic support) while others highlight critical skills and characteristics of the individuals who run interventions, such as identifying as a Black lesbian (see Table 1 for a list of themes and examples of related interventions). Next, we will describe each theme, provide exemplar quotations from participants, and draw connections to both existing research and implications for practice.

\section{| Insert Table 1 approximately here |}

\section{Encourage Community and Human Connection}

While predominant gerontological approaches within the U.S. often promote "selfreliance" as an indicator of successful aging (Cruikshank, 2013), the women participating in the focus groups expressed a need for interventions that promote healthy aging through community building and development of human connection. Such approaches were suggested to help with the aging process in a number of ways, including: (a) having support from Black lesbians and affirming friends and family to help reduce stigma related to health challenges, being "out" as lesbian, and growing older; (b) promoting health through the physical presence of other Black lesbians; (c) tackling loneliness and isolation while growing older; and (d) having a network for caregiving when they face health struggles.

Internalized stigma affects many minority populations but can be a particularly strong obstacle for groups who hold multiple marginalized identities, such as mature Black lesbians. Multiple women discussed how being lesbian in the Black community held remarkable stigma that was rarely acknowledged. Several participants, including a 72-year old woman, voiced an interest in strategies that could help Black lesbians with coming "out" and accepting themselves: 
The biggest thing for me is I did not realize I was a lesbian until I was 50 years old. [We need] to help people...to know that who they are is alright because we've been so oppressed...We're afraid to believe in God and we're told we don't have a right to and we're told by our families we don't have the right to be in our families, that there's something wrong with us. And I think if I had unlimited funds, I would work towards helping people feel that they're good enough from the inside so that they can walk anywhere and be who they are... and know that that's okay.

This participant's words highlight that lesbians may "come out" at any age, including later life, and having an affirming social support network is key in protecting against mental health issues during the coming out process (Beals, Peplau, \& Gable, 2009; Kwon, 2013). Lesbian peer support groups were one recommended intervention to help address this internalized stigma. Other participants discussed feeling stigmatized and isolated as they age, making it difficult to seek support when facing illness. A 48-year-old woman shared:

I am getting older. I'm not as attractive or I'm not as willing to go out there and [be] seen in the community as I was, so I'm not putting myself out there. So, am I gonna be seen?...And when you do have an illness, and then you're sitting at home and you don't have the drove of people coming around you like they did, it plays on your whole psyche of..."[What] did I do to deserve these things?" I find that a lot of us are isolating ourselves instead of reaching out and saying, "I need some help. I need somebody to talk to," verses saying, "I'm at this age and there's such an expectation for us to be wise and knowledgeable of things that we've never been confronted with and heard about in our society," because there is such a stigma on having a mental illness... So you're kinda, you're suffering in silence. 
This woman speaks to the struggle of facing illness, a changing image of one's body, and expectations around being "wise and knowledgeable" about aging even though these are new challenges for her. She calls for women to share these experiences with each other instead of "suffering in silence." Interventions could encourage social connection for Black lesbians through therapeutic support groups, socializing activities, and online chats focused on particular stigmatized topics like mental illness. For example, previous research has documented the positive impact of support group models that include explicit discussion of race and genderbased discrimination for reducing stress among Black women (Mays, 1995)

Some participants said that meeting with other Black lesbians in-person was critical for their well-being. A 41-year-old shared:

I think with the invention of Facebook and things like that, we put a lot [online] and ask for support that way...But also being in the physical presence of others is so important. Physical touch is extremely important. Like being able to hold each other and love each other...I'm like, "We need touch. Like stop with the bullshit and actually touch each other.”...That can help so much with our mental health.

There appear to be few studies of the impact of web-based compared to in-person support groups for older Black lesbians, and thus additional research is warranted. However, many older adults, particularly the old-old, may not have access to or interest in using online support groups; further, the literature in this area may often overstate and oversimplify the benefits of computer use for addressing well-being or loneliness among older adults (Dickinson \& Gregor, 2006).

The women interviewed made clear that community building among Black lesbians would be a critical intervention for addressing the loneliness and isolation that can occur with aging. Isolation and loneliness are well-documented risks for aging older adults (Tomaka, 
Thompson, \& Palacios, 2006) and may be a particularly difficult adjustment for marginalized populations who have typically relied on their communities for socialization in younger adulthood. Suggestions ranged from support and social activity groups to lesbian senior housing and assisted living. An 89-year-old said, "I would like to find a place where lesbians can gather. A peaceful place and nice environment, and I would put money into that, 'cause we don't seem to have a place like that for older lesbians." A 55-year-old participant summed up the importance of Black lesbians having community while aging:

I think the loneliness and isolation piece is very relevant to this topic because as lesbians age, many lesbians don't have children. Many have been ex-communicated from their family of origin, so I think that's a real important topic. And even those of us that do have children, my children don't do anything for me. We're pretty much estranged...I have one of my very good friends, she doesn't have any family. She doesn't have any children. I'm concerned about her aging and being alone. I would take her into [my] house and take care of her if I needed to, but I have a partner, so how does that really work out? Those are some very important components of being in this life because everybody doesn't have family.

This quote highlights the unique struggles around maintaining social connections for Black lesbians, given the greater likelihood of rejection from family of origin. While this participant notes that many lesbians that she knows do not have children, as noted by Gates (2011), 40\% of Black same-sex couples in the U.S. are raising children under the age of 18, and although this rate is lower than that of different-sex Black couples $(51 \%)$, it is notably higher than the rate of childrearing among white same-sex couples (16\%). Thus, concerns about adult children not being present to care for aging Black lesbians may reflect situations where children from 
previous relationships have rejected their mother after she came out as a lesbian or are absent for other reasons, rather than there being no children in the family.

Many of the women discussed strategies for building upon or maintaining their connections to other Black lesbians as they age. Having access to a community of peers may help provide a network of friends who could offer care to one another as they grow older. A 41year-old explained:

[My friends and I are] talking about starting an intentional community, which I also think will help with growing older together and supporting one another...Everyone's not going to have partners to take care of them. Everyone's not going to have children to take care of them... So one of the things that I think is the most important is to have that community to develop your own personal network.

This suggestion for building an intentional caregiving network reflects a pattern of adaptability that has been documented in previous research with older LGBT adults (Brennan-Ing, Seidel, Larson, \& Karpiak, 2014; Fredriksen-Goldsen et al., 2011); such an intentional network may be especially helpful considering that older lesbians may otherwise have a greater struggle identifying known people in their social network who can care for them as they age (FredriksenGoldsen et al., 2011). Helping professionals who work with mid-life and older women can proactively address this issue by working with Black lesbians to establish caregiving networks for when this cohort needs care as they age.

\section{Holistic Care, Mind-Body Techniques, and Complementary \& Alternative Medicine}

Despite the predominance of the Western medical model for health and aging interventions in the U.S., Black women's herstory suggests a skepticism of these approaches and a turning toward other methods of helping that better reflect their culture, resilience, and beliefs 
about the limited effectiveness of traditional medicine (Chao, Wade, Kronenberg, Kalmuss, \& Cushman, 2006). The women in the focus groups spoke of being drawn toward holistic approaches, mind-body techniques, and complementary and alternative medicine. When asked questions about how they would describe a "healthy Black lesbian" and what interventions for healthy aging they would recommend, many of their responses reflected an intersectional and holistic sense of their lives and bodies - their physical well-being, mobility, mental and emotional health, sexuality, cultural and social connectedness, spirituality, and financial health. Such a preference for holistic health has similarities with practices used by other non-white populations, such as the use of Traditional Chinese Medicine with older Asian adults (Park, 2011). Further, Halkitis, Kapadia, Ompad, \& Perez-Figueroa (2015) propose a holistic conceptual framework for aging among gay men that similarly acknowledges the importance of the total person in healthy aging.

When asked to envision what interventions they would like to see for supporting mature Black lesbians, the women described interventions that spanned multiple spheres of life- from socialization to intellectual enrichment, housing, food and nutrition, exercise, physical health, and mental health. For example, one recommendation, suggested by a 55-year-old, was to offer a holistic residential community for mature lesbians:

I would like to see a senior assisted living facility. I would like to see apartments and a community center where you could go and you could listen to music...You could have a yoga instructor... exercise, nutritionist... Just a living enclave where you fill out an application and the only prerequisite being that you be a lesbian over 55 .

In addition to incorporating a holistic lens for interventions, these women also spoke to the use of mind-body techniques, such as meditation, and a general attention to "knowing my body and 
listening to my body," as a 74-year old stated. A growing knowledge base documents the effectiveness of techniques such as yoga, meditation, tai chi, and mindfulness among seniors for improving symptoms of depression, anxiety, and sleep disturbances (D’Silva, Poscablo, Habousha, Kogan, \& Kligler, 2012). Mindfulness meditation, with some cultural adaptations, may assist with stress management and health promotion for African American adults (WoodsGiscombé \& Gaylord, 2014). A number of participants discussed meditation as a useful technique for stress relief - a 71-year old described it as, "Being still and contemplating. Meditation can be very useful for me." A 46-year-old discussed how meditation has helped her to cope with mental and physical health challenges:

You know what I'm going through... especially bipolar disorder and fibromyalgia at the same time, bring a lot of depression... I'm no longer on medication. I was able to wean off and take a [natural] remedy...And then not having money, being self-employed for a very big space, you have to learn how to cope. And so meditation and breathing have become huge for me... I would say that probably is my medicine...

This participant spoke of meditation as a "medicine," and many of the participants said that they actively look for health remedies that can stand in the place of prescription drugs, which were an undesirable option for some of the women. They frequently looked to alternative and complementary medicine approaches, which included remedies passed down through their families, Eastern and aboriginal approaches to medicine, herbs and natural supplements, and smoking marijuana.

A number of the women expressed suspicion about Western approaches and prescription medication. Helping professionals looking to support mature Black lesbians as they age need to be adaptable in formulating interventions. Simply referring a Black lesbian to a medical doctor 
for a health problem may not be appropriate, sufficient, or a match for her needs, and understanding a mature Black lesbian's hesitance to take this route is important. We can work alongside of this population to formulate alternative, effective solutions that are based within this population's lived experience. Some examples might include gerontological interventions that holistically (Portnoi, 1981) assess the needs of older Black lesbians and engage them with appropriate services above and beyond traditional medical care, or mind-body interventions that are culturally adapted for Black women (Woods-Giscombé \& Gaylord, 2014).

\section{Economic Interventions}

Although this sample was highly educated, over one-third of the women had annual incomes below $\$ 30,000$. This pattern of economic hardship is in line with previous survey research on Black sexual minorities (Sears \& Badgett, 2012), as well as qualitative research with a sample of predominantly white older lesbians (Richard \& Brown, 2006). Poverty disproportionately impacts Black Americans compared to whites (Economic Policy Institute, 2012), and socioeconomic status is well-documented as a contributor to major chronic and acute health conditions (see, for example, Braveman, Cubbin, Egerter, Williams, \& Pamuk, 2010). Due to societal discrimination and stigma that aging lesbians have encountered throughout their lives, as well as historic legal barriers to employment, governmental benefits, co-owned housing, and health insurance coverage through partners, lesbians as a group have faced lifelong barriers to financial well-being (Averett, Yoon, \& Jenkins, 2011; Richard \& Brown, 2006), which affect their resources in later life.

A number of the participants discussed how economic interventions - such as community health funds for older lesbians, financial education, and free health clinics—would be of use to them as they age. A 56-year old shared: 
When I was young, even as an out lesbian, there was no real discussion about saving [for] retirement... As women, Black women and lesbians, our economic strength is probably much less than any other social group because women earn less than men, and very often, Blacks less than whites. If we could do some type of intervention [in which] we bring the whole thing of economics... because, you know...let's face it, you gotta have money.

Other women in the focus groups suggested creating a free health clinic to help meet the needs of older Black lesbians who may be uninsured (as was $20 \%$ of our sample) and unable to pay for their care out-of-pocket. This is particularly true in Georgia, a state that has not expanded Medicaid as part of the Affordable Care Act (Kaiser Family Foundation, 2016), leaving many families still uninsured. In 2014, 34\% of lower income LGBT individuals in states that did not expand Medicaid were uninsured, compared to $17 \%$ of LGBT individuals in states that expanded the program (Center for American Progress, 2014). A 90-year old offered: "I would set up a bunch of free health clinics with the best doctors that all that money could afford. Everything in these clinics...would be free to older lesbians." Interventions such as free health clinics, financial literacy programs, and community health funds targeted to mature Black lesbians could address the economic injustices underlying health disparities and lessen the health burden on this population.

\section{Providing Information and Education}

The women in the focus groups expressed some uncertainty about how to gather information to learn about the precise services and resources available to them as they grow older. A 53-year-old proposed:

I think a good program for aging lesbians would be like a transition program, as you're getting older, someone would teach you like, "Hey, these are the programs that are 
[available] to you as far as health care. These are some of the social places where you can go [to] meet people that's of the same age"... So if you [are] one of those people who are like, "I want to know about Medicare and Medicaid and how this is applied to me. If I have a partner, does she get my benefit? Legal information”...Even though you're gay, you still got the same issues as someone that's straight.

As this woman notes, many of these issues are similar as for heterosexual individuals, but there is a need for improved information dissemination among Black lesbians. There are a multitude of aging-related organizations that offer such programming to general audiences of midlife and older adults, such as the AARP and lifelong learning classes for seniors; the women in this study indicate that tailoring such information to Black lesbians would be beneficial to them.

\section{Preferred Provider Identities and Competencies}

The mature Black lesbians in this study expressed a number of characteristics they prefer to see in providers who help promote healthy aging, such as doctors, nurses, gerontologists, and mental health practitioners. Some of the main points of emphasis include having a provider who is: (a) competent and affirming in working with lesbians, (b) someone you can trust who gives you adequate time during a consultation, (c) someone who is preferably a Black woman or Black lesbian, and (d) someone who recognizes the intersectionality of clients/patients served.

Having a lesbian-affirming provider was one of the most frequently discussed desired characteristics for service providers. Some of the women expressed deep concern about widespread homophobia within settings that serve older adults. A 49-year-old discussed what she had witnessed in one setting for seniors:

I did some volunteer work at [senior community]....and one of [the African American residents] turned out to be lesbian, and she talked a lot about having lived her life "out," 
and now not being able to live her life or just to be authentic, and how devastating that was to her, to get old and then have to start lying about who she was. That was an eyeopener for me... I think that that would... sort of softly kill me to have to live in a situation where all of a sudden [I] couldn't be authentically who I was.... I think we probably encounter people all the time that are choosing to live in the closet for survival and we just don't even know it.

Putting lesbian elders in a situation where they are forced back into the closet "for survival" has the potential to worsen their mental and physical health. There is a continued need for education and training about LGBT competency within helping professions, particularly for those working with older adults, so that LGBT seniors receive affirming care (Fredriksen-Goldsen, Hoy-Ellis, Goldsen, Emlet, \& Hooyman, 2014).

Participants also highlighted the importance of finding a helping professional who can be trusted and who gives adequate time for consultations. As part of establishing a sense of trust, some, though not all, of the participants said that they look for helping professionals who share identities with them - particularly, Black female or Black lesbian providers. However, given the overrepresentation of white professionals in many health care professions (Grumbach \& Mendoza, 2008) and the fact that many directories do not list a provider's identities, the women sometimes had difficulty finding such providers. Some tried searching in gay-friendly publications for lists of "affirming" providers. However, there can be a gap in understanding when Black lesbians seek help from white gay or lesbian health professionals, as shared by a 54year-old woman:

You didn't see "Lesbian Black counselor" [in the phone book]. I tried to do my homework on the people that they offered... One woman said she "affirms" relationships. 
So I did see her, but after about 3 weeks of talking to her, older white woman, I was like, "She don't have a clue what I'm talking about."

Finding a Black lesbian provider was seen as a way to locate someone comfortable with the client who could culturally understand what they have experienced in life. To be clear, not all participants felt that a provider's race, gender or sexual orientation had to match their own, and some spoke of how they sought help from Black female providers but found them to be homophobic and not helpful. However, for a number of the women, a provider's identities mattered in help-seeking and building trust. Such evidence points to the need for national initiatives to increase the representation of Blacks and other racial and ethnic minorities within health professions and aging services, similar to pipeline programs organized by the Physicians Medical Forum (n.d.) and Vanderbilt University (Sadick, 2016).

The women interviewed also expressed a desire to find helping professionals who recognize their intersectionality - in other words, people who see and respond to the unique needs of aging Black lesbians and the multitude of identities they hold. A 44-year-old shared: There are a lot of stressors that are put on our lives as Black lesbians, which then affect our physical health. If you're always constantly in a world where you are expected to look a certain way, to be a certain way, to live a certain way, and you don't fit any of those boxes, then that affects your mental health. In the Black lesbian community, there's a lot of issues with substance abuse and mental health issues because when you're dealing with that type of stress, you find ways of trying to medicate that, and therefore every other issue we have or health disparity as Black women is doubled when you think about being a Black lesbian because we have so many other stressors. 
Such words speak to the need for assessing a client as a multidimensional person; gerontologists and other helping professionals can best serve this community when recognizing the multiple, overlapping identities these women hold and the impact on their experience of aging.

\section{Intergenerational Approaches: "We have what the books don't tell, in us"}

Finally, the focus group participants spoke of a need for intergenerational programming. Many of the women said that being around children and mentoring younger lesbians helps them "bounce back" from struggles, gives them energy, and promotes a sense of connection. Several participants said that being around children promotes their happiness and health, including a 63year old woman who said that being around her "grandbabies" kept her well. These statements are in line with much of the research on the psychosocial benefits of intergenerational connections for older adults (Eggers \& Hensley, 2004; Knight, Skouteris, Townsend, \& Hooley, 2014). A 45-year-old participant described how she wanted to stay in community in late life: I want to always have a community that is multi-age. I want to see young people and I want to see old people and I want to see brand new people. I think the only thing that kind of worries me is the idea that maybe I will be shuttled off and playing bingo. I don't wanna play bingo. I wanna find out what your book report was about. I wanna know what's going on with kids.

Some of the participants also expressed a desire to mentor children or younger Black lesbians, which can provide a sense of purpose. One 53-year-old woman aptly described how her generation would like to share "what the books don't tell":

[I would create] a place that seniors could go, but I also want a place where...people could bring their children, because there's...things that [are] still in the senior's mind and books don't give you all of that...There's so much seniors can help with children, and 
especially children that come from single parents and the grandparents may not be still living...The seniors could teach the kids old-school stuff: learning how to sew, learning how to cook simple things, just helping them to grow while they're young... The seniors, we have it in us. We have what the books don't tell, in us.

Interventions that promote exchanges across age cohorts—-such as children visiting senior centers, mentoring programs that match older and younger Black lesbians, or caregiving services that train younger adult volunteers to help out seniors - could address the desires for social exchange expressed by the Black women in our study while also filling other functional needs.

\section{Conclusion}

The goal of this research was to draw from the lives of mature Black lesbians to recommend specific characteristics of interventions that can promote healthy aging for this population. This study had a number of notable strengths, including that it used a relatively large sample of Black lesbians from the community $(N=100)$ and was designed and coordinated by Black lesbians. However, there are also some limitations. Since the study design used focus groups, some recommendations may not have been captured if the women were hesitant to speak about particularly sensitive topics, such as mental health, in front of a group of their peers. Some of the focus group members knew each other outside of the context of this research, which may have impacted the dynamic of the focus groups. Further, our analysis was focused on identifying potential interventions for healthy aging; we cannot draw conclusions about whether the suggestions discussed by the women would actually have a measurable, positive impact on their aging process. However, we have noted throughout our findings how suggested intervention characteristics relate to previous evidence-based research. Our sample was limited to women currently living in Atlanta, GA, although most were not born in the city and did not spend their 
formative years in Atlanta or in the South in general. Their experiences in varying geographic regions may impact their view of aging and their identities as mature Black lesbians in ways we cannot fully determine. There is a need for additional research in other regions of the country, with Black lesbians who were raised in the South, and in rural areas where the aging experiences of mature Black lesbians may look different than that of this sample.

The 100 mature Black lesbian who engaged in this study offered a number of key recommendations for interventions promoting healthy aging in their community. These included: encouraging community and human connection; using holistic approaches, mind-body techniques, and alternative and complementary medicine; providing information and education, and facilitating intergenerational programs (see Table 1 for summary review). They also voiced a preference for certain characteristics of service providers, such as being affirming of lesbians, trustworthy, and sharing identities in common with mature Black lesbians. Such suggestions are ripe for informing design of a future intervention to promote healthy aging - one created, facilitated, and evaluated by mature Black lesbians themselves. Gerontologists and other helping professionals can play a role in supporting the development of such interventions, as well as their evaluation for effectiveness. For example, future research might study whether developing a support network of Black lesbians of multiple generations - who could provide support to older Black lesbians in terms of household tasks, caregiving, transportation, and socialization needs positively impacts the aging process for this population. Our hope is that this study can help guide the development of such efforts in the future to support healthy aging among Black lesbians, as this community faces a disproportionate health burden and is too often ignored in aging services and research. 


\section{References}

Averett, P., Yoon, I., \& Jenkins, C. L. (2011). Older lesbians: experiences of aging, discrimination and resilience. Journal of Women \& Aging, 23, 216-232. doi: $10.1080 / 08952841.2011 .587742$

Beals, K. P., Peplau, L. A., \& Gable, S. L. (2009). Stigma management and well-being: The role of perceived social support, emotional processing, and suppression. Personality and Social Psychology Bulletin, 35(7), 867-879. doi: 10.1177/0146167209334783

Braveman, P.A., Cubbin, C., Egerter, S., Williams, D. R., and Pamuk, E. (2010). Socioeconomic disparities in health in the United States: What the patterns tell us. American Journal of Public Health, 100(1): 186-196. doi: 10.2105/AJPH.2009.166082

Brennan-Ing, M., Seidel, L., Larson, B., \& Karpiak, S. E. (2014). Social care networks and older LGBT adults: challenges for the future. Journal of Homosexuality, 61(1), 21-52. doi: $10.1080 / 00918369.2013 .835235$

Center for American Progress. (2014, November). Moving the needle: The impact of the Affordable Care Act on LGBT communities. Retrieved from https://cdn.americanprogress.org/wp-content/uploads/2014/11/LGBTandACA-report.pdf

Chao, M. T., Wade, C., Kronenberg, F., Kalmuss, D., \& Cushman, L. F. (2006). Women’s reasons for complementary and alternative medicine use: Racial/ethnic differences. Journal of Alternative and Complementary Medicine, 12(8), 719-720. doi:

10.1089/acm.2006.12.719

Collins, P. H. (2009). Black feminist thought. New York, NY: Routledge.

Crenshaw, K. (1989). Demarginalizing the intersection of race and sex: A Black feminist critique of antidiscrimination doctrine, feminist theory and antiracist politics. The University of Chicago Legal Forum, 139-167. 
Cruikshank, M. (2013). Learning to be old: Gender, culture and aging (3rd ed.). Plymouth, UK: Rowman \& Littlefield.

D’Silva, S., Poscablo, C., Habousha, R., Kogan, M., \& Kligler, B. (2012). Mind-body medicine therapies for a range of depression severity: A systematic review. Psychosomatics, 53(5), 407-423. doi: 10.1016/j.psym.2012.04.006

Dickinson, A., \& Gregor, P. (2006). Computer use has no demonstrated impact on the well-being of older adults. International Journal of Human-Computer Studies, 64, 744-753. doi: 10.1016/j.ijhcs.2006.03.001

Economic Policy Institute. (2012). "Key numbers: Poverty.” The state of working America. Washington, D.C.: Economic Policy Institute. Retrieved from http://stateofworkingamerica.org/files/book/factsheets/poverty.pdf

Eggers, S. J., \& Hensley, B. H. (2004). Empowering spirituality and generativity through intergenerational connections. Journal of Religion, Spirituality \& Aging, 17(1-2), 87-108. doi: 10.1300/J496v17n01_05

Farquhar, C., \& Das, R. (1999). Are focus groups suitable for 'sensitive' topics? In R. S. Barbour \& J. Kitzinger (Eds.), Developing focus group research: Politics, theory and practice (pp. 46-63). London, UK: Sage.

Fredriksen-Goldsen, K. I., Hoy-Ellis, C. P., Goldsen, J., Emlet, C. A, \& Hooyman, N. R. (2014). Creating a vision for the future: Key competencies and strategies for culturally competent practice with lesbian, gay, bisexual, and transgender (LGBT) older adults in the health and human services. Journal of Gerontological Social Work, 57(2-4), 80-107. doi: $10.1080 / 01634372.2014 .890690$ 
Fredriksen-Goldsen, K. I., Kim, H., Emlet, C. A., Muraco, A., Erosheva, E. A., Hoy-Ellis, C. P., ... Petry, H. (2011). The Aging and Health Report: Disparities and resilience among lesbian, gay, bisexual, and transgender older adults. Seattle, WA. Retrieved from http://caringandaging.org

Gates, G. J. (2011). Family formation and raising children among same-sex couples. National Council on Family Relations: Family Focus on LGBT Families, pp. F1-F4. Retrieved from http://williamsinstitute.law.ucla.edu/wp-content/uploads/Gates-Badgett-NCFR-LGBTFamilies-December-2011.pdf

Geronimus, A. T., Hicken, M. T., Pearson, J. A., Seashols, S. J., Brown, K. L., \& Cruz, T. D. (2010). Do US black women experience stress-related accelerated biological aging?: A novel theory and first population-based test of black-white differences in telomere length. Human Nature, 21(1), 19-38. doi: 10.1007/s12110-010-9078-0

Gonzales, G., \& Henning-Smith, C. (2015). Disparities in health and disability among older adults in same-sex cohabiting relationships. Journal of Aging and Health, 27(3), 432-453. doi: $10.1177 / 0898264314551332$

Grumbach, K., \& Mendoza, R. (2008). Disparities in human resources: Addressing the lack of diversity in the health professions. Health Affairs, 27(2), 413-422. doi: 10.1377/hlthaff.27.2.413

Halkitis, P. N., Kapadia, F., Ompad, D. C., \& Perez-Figueroa, R. (2015). Moving toward a holistic conceptual framework for understanding healthy aging among gay men. Journal of Homosexuality, 62(5), 571-587. doi:10.1080/00918369.2014.987567 
Kaiser Family Foundation. (2016, July 7). Status of state action on the Medicaid expansion decision. Retrieved from http://kff.org/health-reform/state-indicator/state-activity-aroundexpanding-medicaid-under-the-affordable-care-act/

Knight, T., Skouteris, H., Townsend, M., \& Hooley, M. (2014). The act of giving: A systematic review of nonfamilial intergenerational interaction. Journal of Intergenerational Relationships, 12(3), 257-278. doi:10.1080/15350770.2014.929913

Kwon, P. (2013). Resilience in lesbian, gay, and bisexual individuals. Personality and Social Psychology Review, 17(4), 371-383. doi: 10.1177/1088868313490248

Li, C.-C., Matthews, A. K., Aranda, F., Patel, C., \& Patel, M. (2015). Predictors and consequences of negative patient-provider interactions among a sample of African American sexual minority women. LGBT Health, 2(2), 140-146. doi:10.1089/lgbt.2014.0127

Mays, V. M. (1995). Black women, work, stress, and perceived discrimination: The focused support group model as an intervention for stress reduction. Cultural Diversity in Mental Health, 1(1), 53-65. doi: 10.1037/1099-9809.1.1.53

McIntyre, S. L., Antonucci, E. A., \& Haden, S. C. (2014). Being white helps: Intersections of self-concealment, stigmatization, identity formation, and psychological distress in racial and sexual minority women. Journal of Lesbian Studies, 18(2), 158-173. doi:

$10.1080 / 10894160.2014 .867400$

Office of Research on Women's Health, National Institutes of Health. (2014). Women of color health data book ( $4^{\text {th }}$ edition). Retrieved from http://orwh.od.nih.gov/resources/ policyreports/pdf/WoC-Databook-FINAL.pdf 
Park, K. (2011). Asian medicine and holistic aging. Pastoral Psychology, 60, 73-83. doi: $10.1007 / \mathrm{s} 11089-010-0305-8$

Patton, M. (2002). Qualitative research and evaluation methods (3 ed.). Thousand Oaks, CA: Sage.

Physicians Medical Forum. (n.d.). 2016 Doctors on Board Program. Retrieved from http://pmfmd.com/doctors-on-board/

Portnoi, V. A. (1981). Delivery of geriatric services to black senior citizens. Journal of the National Medical Association, 73(9), 847-851.

Richard, C. A. \& Brown, A. H. (2006). Configurations of informal social support among older lesbians. Journal of Women \& Aging, 18(4), 49-66. doi: 10.1300/J074v18n04

Sadick, B. (2016, February 15). 'Pipeline' programs try to steer minority students to careers in medicine. The Wall Street Journal. Retrieved from http://www.wsj.com/articles/pipelineprograms-try-to-steer-minority-students-to-careers-in-medicine-1455592256

Saldana, J. (2009). The coding manual for qualitative researchers. Thousand Oaks, CA: Sage. Sanchez, R. (2006). On a critical realist theory of identity. In L. M. Alcoff, M. Hames-Garcia, S. P. Mohanty, \& P. M. L. Moya (Eds.), Identity Politics Reconsidered (pp. 31-52). New York, NY: Palgrave MacMillan.

Sears, B., \& Badgett, L. (2012, June). Beyond stereotypes: Poverty in the LGBT Community. Retrieved from http://williamsinstitute.law.ucla.edu/headlines/beyond-stereotypespoverty-in-the-lgbt-community/

Tomaka, J., Thompson, S., \& Palacios, R. (2006). The relation of social isolation, loneliness, and social support to disease outcomes among the elderly. Journal of Aging and Health, 18(3), 359-384. doi: 10.1177/0898264305280993 
Van Sluytman, L. G., \& Torres, D. (2014). Hidden or uninvited? A content analysis of elder LGBT of color literature in gerontology. Journal of Gerontological Social Work, 57(2-4), 130-60. doi: 10.1080/01634372.2013.877551

Weitzman, P. F., Dunigan, R., Hawkins, R. L., Weitzman, E. A., \& Levkoff, S. E. (2001). Everyday conflict and stress among older African American women: Findings from a focus group study and pilot training program. Journal of Ethnic \& Cultural Diversity in Social Work, 10(2), 27-44. doi: 10.1300/J051v10n02_03

Wilkinson, S. (1998). Focus groups in health research: Exploring the meanings of health and illness. Journal of Health Psychology, 3(3), 329-348.

Woods-Giscombé, C. L., \& Gaylord, S. A. (2014). The cultural relevance of mindfulness meditation as a health intervention for African Americans. Journal of Holistic Nursing, 32(3), 147-160. doi: 10.1177/0898010113519010

Woody, I. (2014). Aging out: a qualitative exploration of ageism and heterosexism among aging African American lesbians and gay men. Journal of Homosexuality, 61(1), 145-65. doi:10.1080/00918369.2013.835603

Woody, I. (2015). Lift every voice: Voices of African-American lesbian elders. Journal of Lesbian Studies, 19(1), 50-58. doi: 10.1080/10894160.2015.972755

Zuna Institute. (2010). Black Lesbians Matter. Retrieved from http://zunainstitute.org/2010/research/blm/blacklesbiansmatter.pdf 
Table 1. List of Themes and Example Interventions

\begin{tabular}{lll}
\hline \multicolumn{1}{c}{ Thematic Results } & \multicolumn{1}{c}{ Examples of Related Interventions } \\
\hline $\begin{array}{l}\text { Encourage community and } \\
\text { human connection }\end{array}$ & $\begin{array}{l}\text { Therapeutic peer support groups for mature Black } \\
\text { women focused on "coming out" and reducing } \\
\text { internalized stigma related to sexuality, age, etc. }\end{array}$ \\
$\bullet$ & $\begin{array}{l}\text { Senior housing \& assisted living communities } \\
\text { particularly targeted to older lesbians }\end{array}$ \\
$\bullet$ & $\begin{array}{l}\text { Intentional networks of Black lesbians that offer } \\
\text { caregiving services to women in need }\end{array}$ \\
\end{tabular}

Holistic care, mind-body techniques, \& complementary $\&$ alternative medicine
- Holistic aging services, perhaps offered as part of a senior residential community, that address medical as well as social, emotional, spiritual \& other dimensions of older adult well-being

- Culturally adapted yoga, meditation, mindfulness, or tai chi classes for mature Black lesbians
Economic interventions
- Community health funds for mature Black lesbians

- Financial education targeted to the particular needs of mature Black lesbians

- Free health clinics for LGBT seniors

Providing information and education about aging/health services \& legal needs
- Educational materials about aging and health services that are available in the local community that are affirming of mature Black lesbians

- Info sessions about the unique legal needs and considerations for mature Black lesbians regarding end-of-life care

\begin{tabular}{|c|c|}
\hline $\begin{array}{l}\text { Preferred provider identities } \\
\text { and competencies (affirming, } \\
\text { trustworthy/not rushed, Black } \\
\text { woman/lesbian, recognizes } \\
\text { intersectionality) }\end{array}$ & $\begin{array}{l}\text { - Continuing education/training for health and mental } \\
\text { health professionals about building cultural } \\
\text { competency with mature Black lesbians } \\
\text { - Training and funding to support Black women in } \\
\text { becoming helping professionals who can serve } \\
\text { mature Black lesbians }\end{array}$ \\
\hline Intergenerational approaches & $\begin{array}{l}\text { - Mentorship/caregiving exchange for older and } \\
\text { younger Black lesbians } \\
\text { - Senior services that integrate multiple generations, } \\
\text { such as a senior/youth art class }\end{array}$ \\
\hline
\end{tabular}

